\title{
Analisis Video Comments to Followers Ratio Tiktok Pada 5 Brand yang Sukses Memanfaatkan Tren Tiktok
}

\author{
I Wayan Wiriawan \\ Wiriawan18@gmail.com
}

\begin{abstract}
TikTok is a social media application launched by a Chinese company. TikTok allows users to create 15 -second videos accompanied by music, filters, and several other creative features. In Indonesia, there are 30.7 million active users, making Indonesia the country with the largest TikTok users in the world. The large number of active TikTok users in Indonesia can certainly provide an opportunity for brands to make the TikTok platform a social media marketing platform. There are 5 successful brands capitalizing on TikTok trends as a marketing platform, namely: Chipotle, NBA, Fenty Beauty, Gymshark, and Crocs. The purpose of this study is to calculate the credibility of the TikTok account performance of the Top 5 successful brands capitalizing on TikTok trends. The method used for this research is quantitative exploratory method. The results of this study indicate that brand Chipotle is ranked first and has good account performance credibility.
\end{abstract}

\begin{abstract}
ABSTRAK
TikTok merupakan aplikasi sosial media yang diluncurkan oleh perusahaan asal Tiongkok. TikTok memungkinkan penggunanya membuat video berdurasi 15 detik yang disertai dengan musik, filter, dan beberapa fitur kreatif lainnya. Di Indonesia terdapat 30,7 juta pengguna yang aktif sehingga menjadikan Indonesia sebagai negara dengan pengguna TikTok terbesar di dunia. Maraknya jumlah pengguna TikTok yang aktif di Indonesia tentu dapat memberikan peluang bagi brand untuk menjadikan platform TikTok sebagai platform social media marketing. Adapun 5 brand yang sukses memanfaatkan tren TikTok sebagai platform marketing, yaitu : Chipotle, NBA, Fenty Beauty, Gymshark, dan Crocs. Tujuan dari penelitian ini yaitu untuk menghitung kredibilitas dari performa akun TikTok 5 brand yang sukses memanfaatkan tren TikTok. Metode yang digunakan untuk penelitian ini yaitu metode eksploratif kuantitatif. Hasil dari penelitian ini menunjukan bahwa brand Chipotle mendapatkan peringkat pertama dan memiliki kredibilitas performa akun yang baik.
\end{abstract}

Keyword : Credibility Account TikTok ; Social Media Marketing ; Social Media TikTok ; Video Comments to Followers Ratio ; Brands capitalizing on TikTok 


\section{PENDAHULUAN}

Teknologi informasi dan komunikasi yang telah berkembang dengan pesat mampu menghantarkan manusia untuk menciptakan bentuk baru dalam cara berkomunikasi serta berinteraksi melalui media sosial. Media sosial memberikan pengaruh yang cukup besar, saat ini media sosial diajadikan sarana berkomunikasi dalam setiap aktifitas keseharian bersosial di masyarakat. Komunikasi tidak hanya dapat dilakukan secara fisik, tetapi juga dapat dilakukan dengan menggunakan berbagai aplikasi media sosial di dunia maya. Keunggulan layanan aplikasi sosial media adalah memberikan ruang komunikasi dua arah antara konsumenperusahaan dan konsumen-konsumen.

Dengan pesatnya perkembangan teknologi media sosial, telah memberikan dampak terhadap situs-situs komunikasi, dari yang awalnya hanya sekedar email dan chatting, saat ini sudah banyak jejaring media sosial yang bisa digunakan sebagai alat komunikasi. Contoh aplikasi sosial media yang memiliki banyak pengguna saat ini yaitu TikTok. TikTok merupakan aplikasi yang diluncurkan oleh perusahaan asal Tiongkok. Tiktok memungkinkan penggunanya membuat video berdurasi 15 detik yang disertai dengan musik, filter, dan beberapa fitur kreatif lainnya (Adawiyah 2020).

Kehadiran media sosial TikTok dapat membangun sebuah brand, TikTok juga dapat membangun personal branding pemiliknya (Ishihara and Oktavianti 2021). Di Indonesia, terdapat 30,7 juta pengguna TikTok yang aktif sehingga menjadikan Indonesia sebagai negara dengan pengguna TikTok terbesar di dunia. Maraknya jumlah pengguna TikTok aktif di Indonesia tentu dapat memberikan peluang bagi brand untuk menjadikan platform ini sebagai platform social media marketing. Cukup banyak akun perushaan-perusahaan terkenal yang ada pada tiktok, contohnya seperti brand yang sukses memanfaatkan tren Tiktok. Adapun 5 brand yang sukses memanfaatkan tren TikTok, diantaranya yaitu : Chipotle, NBA, Fenty Beauty, Gymshark, dan Crocs ("5 Brand yang Sukses Memanfaatkan Tren TikTok Q1-2021 Majoo.ID” Pamungkas, 2020)

Penelitian ini menggunakan metode eksploratif kuantitatif, dan akan menghitung menggunakan rasio-rasio yang ada pada TikTok. Pada penelitian (Permana and Meinarni 2021) menjelaskan bahwa terdapat 17 rasio yang ada pada sosial media TikTok dan relevan digunakan sebagai media ukur kredibilitas akun yang ada. Penelitian ini hanya berfokus untuk menghitung kredibilitas Video Comments to Followers Ratio pada 5 brand yang sukses memanfaatkan tren TikTok. Tujuan dari penelitian ini adalah mengetahui kredibilitas performa dari akun TikTok 5 brand yang sukses memanfaatkan tren TikTok menggunakan Video Comments to Followers Ratio.

\section{TINJAUAN PUSTAKA}

Perkembangan bidang teknologi saat ini terjadi begitu pesat. Melalui perkembangan yang terjadi dari waktu ke waktu menimbulkan maraknya aplikasi - aplikasi serta platform media sosial yang bermunculan. Aplikasi yang sangat diminati oleh masyarakat saat ini diantaranya adalah TikTok, Instagram, Twitter, WhatsApp dan yang lain sebagainya. Seiring berjalannya waktu, aplikasi sosial media tersebut dapat menjadi candu bagi kalangan masyarakat. Tidak hanya kalangan remaja yang menggunakan aplikasi sosial media, orang tua bahkan anak-anak juga aktif menggunakan aplikasi sosial media tersebut.

TikTok merupakan jejaring sosial media dalam bentuk video yang umumnya berdurasi 15 detik. Pada aplikasi TikTok pengguna dapat membuat video dengan filter-filter yang spesial 
serta menggunakan lagu yang sedang trending. Selain itu, pengguna dapat membagikan video yang dibuat ke aplikasi lain seperti Instagram atauoun Twitter (PRIANBODO 2018).

Media sosial TikTok sangat diminati oleh generasi saat ini, dengan hampir semua generasi menggunakan TikTok. Target pasarnya sangat besar sehingga aman untuk beriklan di media sosial TikTok. Dengan TikTok, selain dapat digunakan untuk mengekspresikan diri melalui menari, bernyanyi, dan sebagainya, kemudian bisa menjadi pribadi yang kreatif dengan memberikan tips-tips unik, dapat pula memberikan sebuah inovasi dalam mengelolah sebuah barang, melatih diri untuk menjadi pribadi yang kreatif dan penuh inovasi. Saat ini TikTok merupakan media sosial yang memiliki banyak penggemar selain Instagram (Fitri, Pertiwi, and Sary 2019) .

Salah satu ciri khas sosial media TikTok adalah halaman utamanya yang Bernama For Your Page atau FYP. Pengguna yang cukup sering ditayangkan dalam FYP dapat menjadi populer dan memiliki banyak pengikut, yang biasa disebut sebagai seleb TikTok (Putri and Azeharie 2021).

Aplikasi Tiktok dapat meningkatkan mood penggunanya melalui musik dan special effect yang disediakan di aplikasi Tiktok. Aplikasi Tiktok memiliki beberapa manfaat diantaranya menghilangkan stress, sebagai media hiburan di tengah kesibukan, dan sebagai media edukasi bagi masyarakat luas (Saputra, Dhuatu, and Giyato 2020).

Aplikasi TikTok tidak hanya digunakan untuk membuat konten video dengan tujuan menghibur pengguna lainnya. Aplikasi TikTok juga dapat dijadikan peluang bagi brand atau perusahaan sebagai platform social media marketing. Penelitian (Purnamasari and Tutiasri 2021) menyatakan bahwa TikTok berpengaruh positif dan signifikan terhadap minat beli atau berbelanja secara online. Sehingga dengan ini, TikTok mampu memberikan peluang yang sangat tinggi bagi perusahaan-perusahaan dalam melakukan digital marketing.

TikTok dirasakan memiliki kekuatan ataupun pengaruh dalam industri, sehingga menimbulkan kualitas akun yang menentukan strata maupun kredibilitas pemilik akun. Kredibilitas akun TikTok merupakan suatu hal yang cukup penting untuk berbagai kepentingan. Kredibilitas sebuah akun TikTok dapat diukur dari tingkat performa yang dihasilkan secara matematis. Dalam mengukur performa diperlukan skala pengukuran yang tertuang ke dalam rasio.

\section{METODE PENELITIAN}

Penelitian ini menggunakan metode eksploratif kuantitatif untuk mengetahui kredibilitas dari performa akun TikTok 5 brand yang sukses memanfaatkan tren TikTok Q1 2021. Metode eksploratif merupakan penelitian yang memiliki tujuan untuk melakukan eksplorasi atau memperdalam pengetahuan ataupun ide-ide baru mengenai suatu hal yang baru, guna merumuskan permasalahan secara terperinci (Maryam, Isrok'atun, and Aeni 2016).

Tujuan dari penelitian ini yaitu mengetahui nilai kredibillitas dari performa akun TikTok 5 brand yang sukses memanfaatkan tren TikTok Q1 2021. Ada beberapa langkah yang harus dilakukan dalam penelitian ini, sehingga mampu menemukan peringkat pertama akun TikTok brand yang sukses memanfaatkan tren TikTok yang memiliki performa terbaik. Langkahlangkah yang dilakukan pada penelitian ini, diantaranya yaitu : 


\section{Melakukan Eksplorasi Pada Website Untuk Menentukan Objek yang Akan}

Dianalisa.

Eksplorasi ini dilakukan pada beberapa halaman website yang menyediakan informasi mengenai objek yang akan di teliti. Setelah ekslorasi selesai dilakukan, sehingga ditemukan nama-nama brand yang akan dijadikan objek analisa. Setelah melakukan eksplorasi pada halaman website, maka langkah selanjutnya yaitu mencari nama akun TikTok dari masing-masing brand tersebut. Pastikan semua brand memiliki akun pada aplikasi sosial media TikTok.

\section{Menghitung Nilai Rata-Rata Variable Dari 5 Brand yang Sukses Memanfaatkan} Tren Tiktok.

Pada langkah ini, peneliti menghitung nilai variable video comments dan variable followers. Variabel merupakan sesuatu yang memiliki nilai bervariasi dimana nilai tersebut dapat dijadikan sebagai dasar untuk empat data yang berbeda seperti rasio, skala, ordinal, nominal dan internal (Rankuti 2015). Untuk menghitung nilai rata-rata dari variabel video comments dan variabel followers yaitu dengan cara mengambil minimal 10 postingan kemudian di hitung sehingga menemukan nilai rata-rata dari masing-masing variabel.

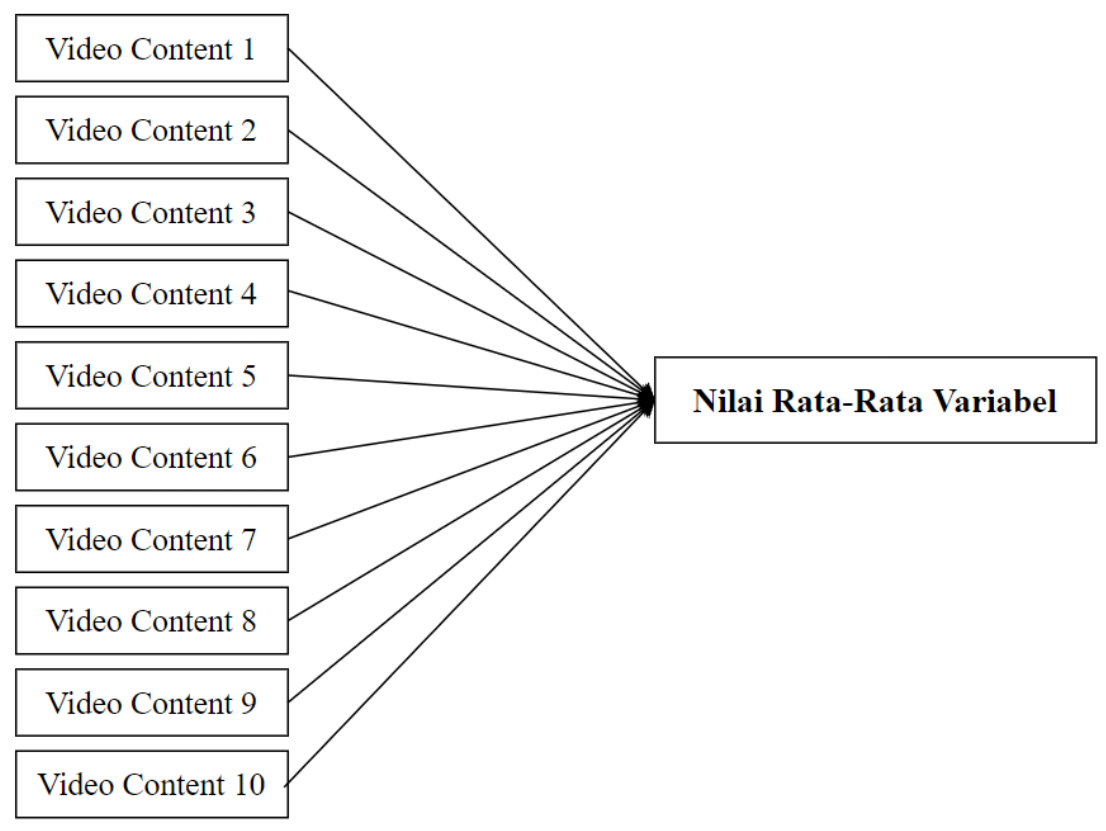

Gambar 1. Analisa Nilai Rata-Rata Variabel.

\section{Menghitung Nilai Kredibilitas Rasio}

Untuk menghitung nilai kredibilitas dari video comments to followers ratio, peneliti menggunakan cara membagi nilai variabel pertama dengan nilai variabel kedua. Jika video comments memiliki nilai 300 dan followers memiliki nilai 600, maka cara menghitungnya yaitu $300: 600=0,5$. Dengan begitu nilai dari video comments to followers ratio adalah 0,5 . 


\section{Menentukan Peringkat Pada Akun TikTok}

Pada langkah terakhir yang dilakukan pada penelitian ini yaitu menentukan peringkat pada masing-masing rasio yang ada. Pada penentuan peringkat perlu melihat karakteristik dari rasio yang di teliti. Jika karakteristik rasio merupakan rendah, maka objek yang memiliki nilai terendah akan mendapatkan angka 5 dan objek yang memiliki nilai tertinggi akan mendapatkan angka 1 . Namun jika rasio memiliki karakteritik tinggi maka objek yang mendapatkan nilai tinggi akan mendapatkan angka 5 dan objek yang mendapatkan nilai terendah akan mendapatkan angka 1. Setelah mendapatkan hasil kredibilitas ratio maka dapat disimpulkan objek yang mana mendapatkan peringkat 1 sampai dengan peringkat 5 .

\section{HASIL DAN PEMBAHASAN}

Akun TikTok dari 5 Brand yang Sukses Memanfaatkan Tren Tiktok Q1-2021, diantaranya:

\section{Chipotle}

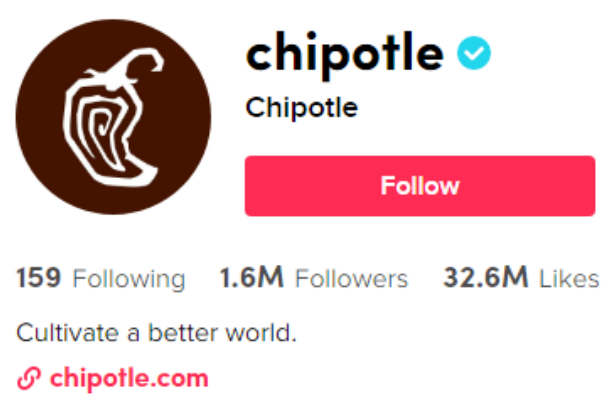

Gambar 1. Akun Ciphotle

Sumber : https://www.tiktok.com/@ chipotle (akses pada 21-10-2021)

\section{NBA}

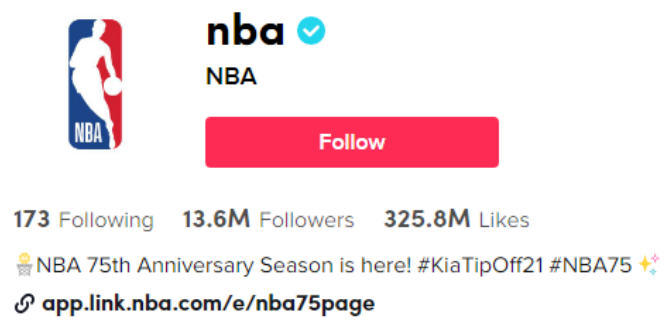

Gambar 2. Akun NBA

Sumber : https://www.tiktok.com/@nba (akses pada 21-10-2021)

\section{Fenty Beauty}




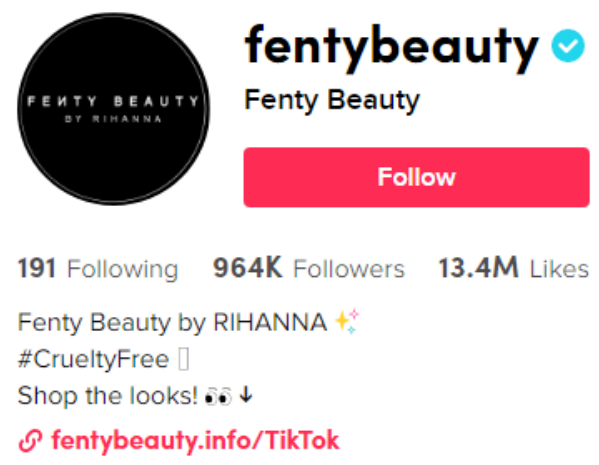

Gambar 3. Akun TikTok Fenty Beauty

Sumber : https://www.tiktok.com/@fentybeauty (akses pada 21-10-2021)

\section{Gymshark}

\section{gymshark}

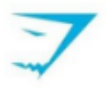

Gymshark

Follow

108 Following 3.4M Followers 50.8M Likes

Nothing to do with sharks.

Something to do with the gym.

$\odot$ gym.sh/Gymshark-homepage

Gambar 4. Akun Tiktok Gymshark

Sumber : https://www.tiktok.com/@ gymshark (akses pada 21-10-2021)

\section{Crocs}

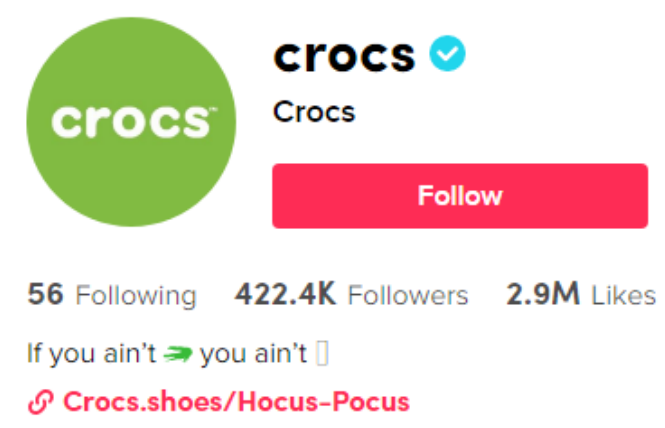

Gambar 5. Akun TikTok Crocs

Sumber : https://www.tiktok.com/@crocs (akses pada 21-10-2021) 
Dari kelima akun TikTok 5 Brand yang Sukses Memanfaatkan Tren Tiktok Q1-2021, peneliti menemukan nilai dari masing-masing variabel yang ada untuk menghitung rasio Video Comments to Followers dari setiap akun. Pada akun TikTok terdapat 7 variabel, diantaranya yaitu :

1. Likes

2. Followers

3. Following

4. Video Likes

5. Video Comments

6. Video Share

7. Video Views

Dari ketujuh variabel tersebut peneliti hanya fokus untuk menemukan hasil dari 2 variabel, yaitu :

1. Video Comments

2. Followers

Dari kedua variabel tersebut kemudian dianalisa sehingga menemukan nilai rata-rata dari variabel video comments dan variabel followers. Untuk menghitung nilai rata-rata dari variabel video comments dan variabel followers yaitu dengan cara mengambil minimal 10 postingan kemudian di hitung sehingga menemukan nilai rata-rata dari masing-masing variabel. Berikut merupakan tabel nilai rata-rata dari masing-masing 5 Brand yang Sukses Memanfaatkan Tren Tiktok, yaitu :

Tabel 1. Analisa Nilai Rata-Rata Nilai Variabel Video Comments dan Followers Akun TikTok Chipotle

\begin{tabular}{|c|r|r|}
\hline No & \multicolumn{1}{|c|}{$\begin{array}{c}\text { Video } \\
\text { Comment }\end{array}$} & \multicolumn{1}{c|}{ Followers } \\
\hline 1 & 2.410 & 1.600 .000 \\
\hline 2 & 27.000 & 1.600 .000 \\
\hline 3 & 10.100 & 1.600 .000 \\
\hline 4 & 177 & 1.600 .000 \\
\hline 5 & 66 & 1.600 .000 \\
\hline 6 & 982 & 1.600 .000 \\
\hline 7 & 292 & 1.600 .000 \\
\hline 8 & 137 & 1.600 .000 \\
\hline 9 & 115 & 1.600 .000 \\
\hline 10 & 275 & 1.600 .000 \\
\hline Total & 4.155 & 1.600 .000 \\
\hline
\end{tabular}

Tabel 2. Analisa Nilai Rata-Rata Nilai Variabel Video Comments dan Followers Akun TikTok NBA 


\begin{tabular}{|c|c|c|}
\hline No & $\begin{array}{c}\text { Video } \\
\text { Comment }\end{array}$ & Followers \\
\hline 1 & 34 & 13.500 .000 \\
\hline 2 & 62 & 13.500 .000 \\
\hline 3 & 38 & 13.500 .000 \\
\hline 4 & 45 & 13.500 .000 \\
\hline 5 & 121 & 13.500 .000 \\
\hline 6 & 61 & 13.500 .000 \\
\hline 7 & 67 & 13.500 .000 \\
\hline 8 & 303 & 13.500 .000 \\
\hline 9 & 127 & 13.500 .000 \\
\hline 10 & 65 & 13.500 .000 \\
\hline Total & 92 & 13.500 .000 \\
\hline
\end{tabular}

Tabel 3. Analisa Nilai Rata-Rata Nilai Variabel Video Comments dan Followers Akun TikTok Fenty Beauty

\begin{tabular}{|c|c|c|}
\hline No & $\begin{array}{c}\text { Video } \\
\text { Comment }\end{array}$ & Followers \\
\hline 1 & 301 & 961.000 \\
\hline 2 & 449 & 961.000 \\
\hline 3 & 39 & 961.000 \\
\hline 4 & 68 & 961.000 \\
\hline 5 & 27 & 961.000 \\
\hline 6 & 203 & 961.000 \\
\hline 7 & 107 & 961.000 \\
\hline 8 & 217 & 961.000 \\
\hline 9 & 244 & 961.000 \\
\hline 10 & 158 & 961.000 \\
\hline Total & 181 & 961.000 \\
\hline
\end{tabular}

Tabel 4. Analisa Nilai Rata-Rata Nilai Variabel Video Comments dan Followers Akun TikTok Gymshark

\begin{tabular}{|c|c|c|}
\hline No & $\begin{array}{c}\text { Video } \\
\text { Comment }\end{array}$ & Followers \\
\hline 1 & 200 & 3.300 .000 \\
\hline 2 & 179 & 3.300 .000 \\
\hline 3 & 182 & 3.300 .000 \\
\hline 4 & 11 & 3.300 .000 \\
\hline 5 & 11 & 3.300 .000 \\
\hline 6 & 26 & 3.300 .000 \\
\hline 7 & 16 & 3.300 .000 \\
\hline
\end{tabular}




\begin{tabular}{|c|r|r|}
\hline 8 & 72 & 3.300 .000 \\
\hline 9 & 36 & 3.300 .000 \\
\hline 10 & 18 & 3.300 .000 \\
\hline Total & 75 & 3.300 .000 \\
\hline \multicolumn{3}{|c|}{ Sumber : Pengolah Data Excel }
\end{tabular}

Tabel 5. Analisa Nilai Rata-Rata Nilai Variabel Video Comments dan Followers Akun TikTok Crocs

\begin{tabular}{|c|c|c|}
\hline No & $\begin{array}{c}\text { Video } \\
\text { Comment }\end{array}$ & Followers \\
\hline 1 & 18 & 418.700 \\
\hline 2 & 59 & 418.700 \\
\hline 3 & 26 & 418.700 \\
\hline 4 & 6 & 418.700 \\
\hline 5 & 757 & 418.700 \\
\hline 6 & 109 & 418.700 \\
\hline 7 & 30 & 418.700 \\
\hline 8 & 912 & 418.700 \\
\hline 9 & 108 & 418.700 \\
\hline 10 & 137 & 418.700 \\
\hline Total & 216 & 418.700 \\
\hline
\end{tabular}

Setelah menghitung nilai rata-rata tersebut, maka akan menemukan hasil akhir nilai ratarata dari variabel video comments dan followers.

Tabel 6. Nilai Variabel Pada Akun TikTok 5 Brand yang Sukses Memanfaatkan Tren Tiktok Q1-2021

\begin{tabular}{|l|r|r|r|r|r|}
\hline \multicolumn{7}{|c|}{ Tabel Nilai Masing-Masing Variable } \\
\hline \multicolumn{1}{|c|}{ Variable } & \multicolumn{1}{c|}{ Chipotle } & \multicolumn{1}{c|}{ NBA } & Fenty Beauty & Gymshark & \multicolumn{1}{c|}{ Crocs } \\
\hline Video Comments & 4.155 & 92 & 181 & 75 & 216 \\
\hline Followers & 1.600 .000 & 13.500 .000 & 961.000 & 3.300 .000 & 418.700 \\
\hline \multicolumn{7}{|c|}{ Sumber : Pengolah Data Excel }
\end{tabular}

Pada akun TikTok terdapat 17 rasio yang relevan digunakan untuk mengukur kredibilitas pada masing-masing akun. Namun pada penelitian kali ini hanya berfokus untuk menghitung Video Comments to Followers Ratio. Untuk menghitung kredibilitas dari masing-masing akun TikTok setiap brand, peneliti menghitung dengan cara : variabel 1 akan dibagi dengan variabel 2 , sehingga ditemukan hasil analisisa dari rasio tersebut.

Tabel 7. Hasil Perhitungan Rasio Akun TikTok 
Tabel Rasio

\begin{tabular}{|c|l|c|c|c|c|c|}
\hline No & \multicolumn{1}{|c|}{ RATIO } & Chipotle & NBA & $\begin{array}{c}\text { Fenty } \\
\text { Beauty }\end{array}$ & Gymshark & Crocs \\
\hline 1 & $\begin{array}{l}\text { Video Comments to } \\
\text { Followers Ratio }\end{array}$ & 0,00259688 & 0,00000681 & 0,00018835 & 0,00002273 & 0,00051588 \\
\hline
\end{tabular}

Sumber : Pengolah Data Excel

Video Comments to Followers Ratio memiliki karakteristik yang tinggi, artinya semakin tinggi nilai yang dihasilkan maka semakin baik kredibilitas dari performa akun tersebut. Untuk memberikan peringkat pada masing-masing Brand yang Sukses Memanfaatkan Tren Tiktok, peneliti memberikan angka 5 kepada brand yang mendapatkan nilai tertinggi dan angka 1 untuk brand yang mendapatkan nilai terendah. Berikut merupakan tabel urutan nilai yang dihasilkan oleh masing-masing Brand yang Sukses Memanfaatkan Tren Tiktok.

Tabel 8. Nilai Rasio Akun TikTok Top 5 Brand yang Sukses Memanfaatkan Tren Tiktok Q1-2021

\begin{tabular}{|c|c|c|c|c|}
\hline \multicolumn{5}{|c|}{ Tabel Peringkat } \\
\hline Chipotle & NBA & Fenty Beauty & Gymshark & Crocs \\
\hline 5 & 1 & 3 & 2 & 4 \\
\hline
\end{tabular}

Dari Tabel Nilai Rasio Akun TikTok 5 Brand yang Sukses Memanfaatkan Tren Tiktok Q1-2021 dapat simpulkan bahwa Chipotle mendapatkan nilai tertinggi untuk rasio Video Comments to Followers. Sedangkan akun TikTok NBA mendapatkan nilai terendah untuk rasio ini. Jadi, pada penelitian ini Chipotle memiliki kredibilitas performa yang lebih baik dibandingkan dengan brand yang lainnya.

\section{KESIMPULAN}

Tujuan dari penelitian ini adalah mengetahui kredibilitas performa dari akun TikTok 5 Brand yang Sukses Memanfaatkan Tren Tiktok menggunakan Video Comments to Followers Ratio. Top 5 Brand tersebut diantaranya: Chipotle, NBA, Fenty Beauty, Gymshark, dan Crocs. Dari kelima brand tersebut dapat disimpulkan bahwa :

1. Peringkat pertama diraih oleh brand Chipotle dengan nilai tertinggi yaitu 0,00259688

2. Peringkat kedua diraih oleh brand Crocs dengan nilai 0,00051588

3. Peringkat ketiga diraih oleh brand Fenty Beauty dengan nilai 0,00018835 
4. Peringkat keempat diraih oleh brand Gymshark dengan nilai 0,00002273

5. Peringkat kelima diraih oleh brand NBA dengan nilai terendah yaitu 0,00000681 


\section{DAFTAR PUSTAKA}

Adawiyah, Dwi Putri Robiatul. 2020. "Pengaruh Penggunaan Aplikasi TikTok Terhadap Kepercayaan Diri Remaja Di Kabupaten Sampang.” Jurnal Komunikasi 14 (2): 135-48. https://doi.org/10.21107/ilkom.v14i2.7504.

Fitri, Annisa Nurintha, Lestari Bunga Pertiwi, and Marisa Puspita Sary. 2019. "Pengaruh Media Sosial Tiktok Terhadap Kreativitas Mahasiswa Ilmu Komunikasi Universitas Negeri Jakarta Angkatan 2019." Jurnal Komunikasi dan Teknologi Informasi 13(1): 3746.

Ishihara, Yemikaori Yumna Ulya, and Roswita Oktavianti. 2021. "Personal Branding Influencer Di Media Sosial TikTok.” Koneksi 5 (1): 76-82. https://doi.org/10.24912/KN.V5I1.10162.

Maryam, Siti, Isrok'atun Isrok'atun, and Ani Nur Aeni. 2016. "PENDEKATAN EKSPLORATIF UNTUK MENINGKATKAN KEMAMPUAN REPRESENTASI MATEMATIS DAN KEPERCAYAAN DIRI SISWA.” Jurnal Pena Ilmiah 1 (1): 55160. https://doi.org/10.23819/PI.V1I1.2984.

Permana, I Putu Hendika, and Ni Putu Suci Meinarni. 2021. "Ratio Analysis on Tiktok (Social Media) for Qualitative Research Using Explorative Methods." Jurnal Ekonomi \& Bisnis JAGADITHA 8 (1): 30-38. https://doi.org/10.22225/JJ.8.1.2944.30-38.

PRIANBODO, BAGUS. 2018. “PENGARUH 'TIKTOK' TERHADAP KREATIVITAS REMAJA SURABAYA," December.

Purnamasari, Nurjihan Pricillia, and Ririn Puspita Tutiasri. 2021. "Analisis Resepsi Remaja Perempuan Terhadap Gaya Hidup Berbelanja Fashion Melalui Tayangan Video 'Belanja Gak Aturan’ Dalam Akun Tiktok @handmadeshoesby.” Jurnal Representamen 7 (01). https://doi.org/10.30996/REPRESENTAMEN.V7I01.5129.

Putri, Shani Dwi, and Suzy Azeharie. 2021. "Strategi Pengelolaan Komunikasi Dalam Membentuk Personal Branding Di Media Sosial Tiktok." Koneksi 5 (2): 280-88. https://doi.org/10.24912/KN.V5I2.10300.

Pamungkas, Ajar. 2020. "5 Brand Yang Sukses Memanfaatkan Tren TikTok.” https://majoo.id/blog/detail/5-brand-yang-sukses-memanfaatkan-tren-tiktok (October 27, 2021).

Rankuti, Freddy. 2015. "Buku Riset Pemasaran.” 2015.

Saputra, Vicky Rian, Chantiq Hast Dhuatu, and Giyato Giyato. 2020. "Pemanfaatan Aplikasi Tiktok Sebagai Mood Booster (the Usage of Tiktok App To Increase Mood Level)." Indonesian Fun Science Award 2(1): 216-26. https://proceedings.sgu.ac.id/ifsj/index.php/ifsj/article/view/53. 